\title{
Active Learning Strategies in an Online Educational Technology Applications Course: The Value of Narratives
}

\author{
John P. Egan \\ The University of British Columbia, Vancouver, BC, Canada
}

john.egan@ubc.ca

\begin{abstract}
Material published as part of this publication, either on-line or in print, is copyrighted by the Informing Science Institute. Permission to make digital or paper copy of part or all of these works for personal or classroom use is granted without fee provided that the copies are not made or distributed for profit or commercial advantage AND that copies 1) bear this notice in full and 2) give the full citation on the first page. It is permissible to abstract these works so long as credit is given. To copy in all other cases or to republish or to post on a server or to redistribute to lists requires specific permission and payment of a fee. Contact Publisher@InformingScience.org to request redistribution permission.
\end{abstract}

This paper describes the development of a new applications course in the University of British Columbia's Master of Educational Technology (MET) post-graduate educational technology program. Its particular focus is the use of active learning strategies inquiry - and problem-based learning (IBL and PBL) - and the narratives used in the IBL and PBL activities in the course. A synopsis of student evaluation of teaching data and some lessons learned are also included.

Many educators who pursue post-graduate study in educational technology have a range of motivations. For some, material concerns - subsequent increases in wages upon degree completion (particularly when amortized over multiple years of service), or scope for promotion within the field - are perhaps paramount. Most, one hopes, are motivated by desires to improve practice and expand knowledge. Educational professionals who enroll in programmes like the University of British Columbia's Master of Educational Technology (or MET) often do so to acquire or advance a range of competencies, including those related to educational design and the creation of educational collateral (including, but not limited to, building materials to be delivered online): for the latter, the acquisition of new technical skills is usually required.

Educational technology is a field that changes daily, and can fairly seduce educators with the "new and shiny," In my own practice I have fallen into this trap: something seems perfect for my classes, though in trying to implement it, things don't quite turn out as anticipated. From my experience - as an instructor, instructional designer, and educational researcher - technical skills are only well-served when rooted in the purposeful, evidence-informed selection of technologies based on pedagogical priorities. Until recently there were no course offerings in the MET that focused on educational technology selection, development and deployment.

This paper describes aspects of the development and delivery of a new MET course, Learning Technologies: Selection, Design and Application (ETEC565A). In particular, this paper examines the integration of narrative, active learning activities that allow learners to develop a nuanced un-

derstanding of technology selection, development and deployment via the examination of a number of narrativebased scenarios.

Keywords problem based learning, inquiry based learning, online

\section{UBC's MET Program}

The University of British Columbia's wholly online Master of Educational 
Technology program (MET; http://met.ubc.ca/) has been in operation since 2002. Since then over 200 learners have completed the MET, studying on either a full-time or part-time basis. Most are educators working at the primary, secondary or tertiary levels, though significant numbers of workforce training professionals, IT consultants, educational designers, and non-profit managers have also enrolled. MET students include those based in Canada, the United States, Mexico, Asia, Europe, the Caribbean, and South Pacific.

From its inception, the MET's emphasis has been on informed, critical analysis of the implementation of technology in learning environments. In addition to core courses in research methods, instructional design, educational technology foundations, and learning theory, MET students choose from a range of elective courses. There are courses focused around subject matters such as math and science, or liberal arts education; others focus on the changing notion of texts in the digital age, indigeneity and educational technology, among others.

All MET students have the option to complete a summative capstone e-portfolio project in lieu of a final course: this e-portfolio synthesizes the depth and breadth of their learning in the programme. A capstone activity (e-portfolio, graduating paper or thesis project) is required for British Columbia K-12 teachers to be eligible for an incremental salary increase for post-graduate studies in education. Most MET students, in fact, elect the e-portfolio, whether they are K-12 educators or not.

\section{The Course}

There has been interest in an applications course from the very beginning of the MET. However, for a number of reasons ETEC565A was only launched in May 2009. These include the challenge of creating a course relevant to students of all skill levels (from intrigued novices to train-thetrainer experts), relevant across the overall body of MET students, regardless of contexts of practices.

That the course needed to be delivered in a wholly online, largely asynchronous environment with students across multiple time zones, added another layer of complexity.

However, once the initial proposal for ETEC565A was approved by program leadership, the development process moved apace rather quickly. The core development team included three course co-authors from the University of British Columbia's Office of Learning Technology ${ }^{1}$ :

- Managing Director Michelle L. Lamberson, a recognized international expert in educational technology;

- Senior Manager Distance and Blended Learning Jeff Miller, who has been involved with the MET since its inception as both its primary instructional designer and as an instructor and course author for several courses; and

- Instructional Designer and Project Manager (also subsequent course instructor, who is the author of this paper) John Egan, who had previously designed and delivered a similar applications course in a blended (face-to-face and online) environment in the university's Bachelor of Education teacher certification program.

${ }^{1}$ Subsequent to the launching of ETEC565A, the Office of Learning Technology has become part of a new service unit at UBC: the Centre for Teaching, Learning and Technology (http://ctlt.ubc.ca/) 
As we three sat down to develop the course, one key question informed our work: what sorts of core competencies would we expect someone who had completed a post-graduate qualification in educational technology to possess?

Having taken a competency-based approach to ETEC 565A does not mean our focus was wholly upon instrumental, "how-to" technical skills. Competency-based education, "the habitual and judicious use of communication, knowledge, technical skills, ... reasoning, emotions, values, and reflection in daily practice for the benefit of the individual and community being served" (Epstein \& Hundart, 2002), is structured around identified competencies required to demonstrate comprehensive knowledge at the professional level. Resultantly we included a range of competencies, including knowledges, attitudes, skills, and literatures related to the selection, design and application of educational technology. Our design was incremental, with increasing levels of complexity and sophistication in the course materials week after week.

For ETEC 565A the core competencies are:

1. A solid understanding of key literatures related to tool selection, learning theory and learning technology deployment best practices

2. Familiarity with professional standards related to educational technology

3. Ability to create a learning management system (LMS) course site with a customized graphical user interface (GUI)

4. Creation of a sophisticated assessment object (quiz or exam), using a range of question types and assessment strategies

5. Development and delivery of a pedagogically purposeful digital story

6. Use of weblogs and wikis for site design, as learning objects, and for e-portfolio assessment

7. Mindfulness of issues related to intellectual property, confidentiality, and data ownership

8. Design for accessibility

9. An ongoing practice of self-reflection

These represent much of the what and why aspects of the course. In terms of the how-to, our design for ETEC565A is built around collaborative learning. All too often educators are encouraged - or required - to work in isolation. As a result, successful educators need to be self-directed and motivated. In areas of practice where self-confidence is high, this autonomy is an asset; when faced with moving outside one's competence zone, this is in reality de facto isolation.

Across the MET student community there is a wealth of knowledges and skills: collegial support and advice are positioned firmly at the centre of most aspects of the program. ETEC 565A has been designed in a way that purposefully leverages this, making collaborative learning - formal and informal - as integral to success in the course. Early in the development process we identified inculcating a learning community, ideally one that formed the basis of an ongoing community of practice after course (and programme) completion, as important.

\section{Active Learning: IBL and PBL}

All ETEC565A learning activities are informed by constructivist (Piaget, 1950) principles. Required course readings either serve as the focus of early course discussions (where canonical readings are examined so they can be applied subsequently throughout the course), or as background reading for the exploration of specific competencies in specific units of study. Learners 
are assessed based on their appropriate integration of relevant literatures, rather than being asked to regurgitate the contents of any particular readings.

Aside from course readings, most of the learning activities in ETEC 565A are interactive, including weekly asynchronous class-wide discussion forums. These discussions fall into two broad categories: the reflective application of a reading to one's own experience - as educator, learner or other educational stakeholder - or responses to real-world scenarios. For the latter, we used pedagogical approaches such as inquiry-based learning and problem-based learning, which were adapted for this course and the MET programme.

One of the challenges in an applications course is the (very human) tendency to rush into solution identification prior to definition of the issue, challenge or problem. Inquiry-based learning (IBL) "the creation of a classroom where students are engaged in essentially open-ended, student- centered, hands-on activities," (Colburn, 2000) is one instructional strategy to mitigate such risks by allowing learners to develop critical questioning (as a specific type of critical reasoning) skills. Inquiry-based learning positions the development of questions as integral to the deep learning process. According Audet (2005), the commonalities across various models of inquiry-based learning are:

- “Ask an answerable question or identify a researchable problem

- Develop a plan and take some form of action

- Gather resources: analyze and summarize information

- Draw conclusions and report findings

- Reflect on the process (p. 14)"

Early in the course, students are given a scenario (Benoît; described in the next section) and asked to come up with the one important question they think is most relevant to the scenario presented. As world-class problem solvers used to figuring things out on their own, staying on-task proves challenging for what is a new pedagogical experience for many. As the discussion unfolds, inevitably some students post two or three questions: in requiring them to either pick one or come up with one alternative, they are forced to look more comprehensively at the scenario. In the postdiscussion synthesis I explain what IBL is, its purposes and benefits, and why we started out there.

However, the inclination to find solutions needs to be nurtured as well: thus we use problembased learning (PBL) in many subsequent learning activities (including Lenora; also described in the next section). Biggs (2003) describes problem-based learning as a pedagogical approach that "reflects the way people learn in real life; they simply get on with the solving the problems life puts before them with whatever resources are to hand." (p. 232). Most of the learning activities in ETEC565A are PBL, IBL or hybrid PBL/IBL scenarios.

Both these approaches share a common structure: a "trigger" scenario, availability of a range of resources to be consulted, and a limited timeframe in which to complete their work. For IBL or PBL to work well, there is a great deal of preliminary design work: the trigger and resources must be vetted in a way that there's little scope for learners to get off track (Wordsmithing the materials, as well as a copious academic review of each, are particularly important). In terms of assessment, these learning activities are all "pass/fail." All are required to be substantively completed, though they are not summatively assessed. Learner engagement with these activities has not been an issue; in fact often the class needs to prodded to move on to the next activity when the discussions are especially rich! 


\section{The Narratives}

A total of seven inquiries or problems were each the focus of a specific unit's learning activities: with 13 units (each a week long) in the course, these learning activities constituted a significant proportion of learner workload. Each narrative was fictive: in other words, the specifics of each were based on real-world issues, contexts and experiences, but the personae in each were fictional. In using fictive narratives, we could integrate a number of external resources that students could draw upon to respond to each narrative - and use subsequently in their own practices, if they so wished.

Given the range of educational contexts in which MET learners work, we tried to integrate narratives reflective of that varied experience. Thus, primary, secondary, post-secondary and adult and community education sectors were each the focus of at least one narrative. Similarly, to reflect the multicultural nature of Canadian society, we ensured a range of cultural experiences - from the names of protagonists to the issue at hand-were reflected.

We specifically integrated two narratives related to Aboriginal education in Canada. There have been some tensions in Canada about discourses that perpetuate stereotypes about Aboriginal persons as poorly educated, drug or alcohol addicted, violent, or criminal. We saw ETEC565A as an opportunity to challenge these racist ideas; as a result we developed one narrative that positions the challenges faced by on-reserve Aboriginal educators as one significantly of geographic distance-similar, though not identical, to the challenges other rurally situated educators face. The other Aboriginal narrative focused on the efforts of a non-Aboriginal educator endeavouring to bring aspects of local Aboriginal experience into his urban Canadian classroom.

These narratives were developed to allow learners to find multiple linkages to their own practices, contexts and experiences.

Below are the specific texts for each narrative, as well as the description of the learning activity from the course materials. The narratives are in italics to facilitate differentiation between the narratives and activity descriptions.

\section{Benoît}

Benoit is a sessional instructor in the English department of a large, research-intensive university. Previously he has used WebCT to disseminate lecture notes and readings for his face-to-face Business Writing course.

His department head has approached him about offering an online version of Business Writing. However, WebCT is no longer available at his university and Benoit must choose either WebCT/Vista or Moodle. WebCT/Vista is the university's "official" LMS and has university-wide IT support, but the Help Desk is difficult to get a hold of and can be very slow in responding to e-mail. Moodle is hosted within the Faculty of Arts, but operates as a stand-alone tool with no real technical support: instructors need to set up their own courses from scratch. More and more faculty and instructors in the English Department now use Moodle, since it isn't administered by IT support: less paperwork, less red tape.

Benoît is very comfortable in the design mode of WebCT; he has also done some general web design, mostly for personal use. In terms of web design he's developed content, uploaded it via FTP and then left it there. He's heard from colleagues that WebCT/Vista is dreadful, that doesn't have half the functionality of WebCT, though he has not yet had time to do any evaluation himself.

Because of his teaching load, Benoît estimates he could spend up to 5 hours a week de- 
veloping the online version of Business Writing. The course would go live next semester.

\section{Discussion questions}

Please answer in the discussion forum:

1. Moodle or WebCT/Vista for Benoît? How might Benoît go about deciding whether to go with Moodle or WebCT/Vista? What questions might he ask himself? Come up with one specific question and post it in the Benoit discussion thread. Be sure to explain why this is an important question.

2. Benoît's time How much development time (in weeks) would you estimate Benoît would need to develop Business Writing, the online version? Post your estimation in weeks in the Module 2: Business Writing development timeframe discussion thread. Be sure to explain how you came up with this number.

\section{Lenora}

Lenora is a grade 4 teacher at the Eliza Archie Memorial School, located on the Tsq'escenemc Canim Lake Band reserve. Last year she attended an anti-bullying professional development (pro-d) workshop offered by SD 83 (North Okanagan). There was a lot of valuable information in the session, but Lenora felt it often wasn't culturally relevant for her community. When she discussed her experience with peers in the Cradleboard Teaching Project Teacher's Circle (http://www.cradleboard.org/), others agreed. And many had stories to share about bullying in their band schools.

Indigenous online communities of practice like Cradleboard have really helped Lenora develop her own reflective practice. She's decided to create an online anti-bullying resource for band teachers - a sort of online pro-d day - that offers support and suggestions from other Aboriginal educators and their allies.

But Lenora's web access is dial-up only. It can take a really long time to upload and download files. Plus she's never created a web site before and doesn't know anything about where one puts a website.

\section{Discussion question}

Is a website the way to go for Lenora - why or why not? Post your estimation in weeks in the Pro-D discussion thread. Be sure to explain how you came up your answer.

\section{Anju}

Anju is a dietician in Port Alberni, BC. She works part-time at both a nearby senior's home and a community centre. "Port" as it's known locally, is an ethnically diverse community whose economy is largely resource-based.

One common community health issue she provides care for is late onset (or "Type 2") diabetes. In fact, among South Asian and Chinese new Canadian women over age 45 in Port there is a diabetes epidemic. An integral part of self-care for adult diabetics is about diet: eating healthily and understanding the role different foods play in maintaining blood glucose levels.

All of Anju's clients are fluent in spoken English, but struggle with materials written in English. Those who attend her one-hour workshops say they help a lot ... but it's difficult to remember all the information afterwards.

Anju thought she might videotape her next workshop and then create a DVD. That way clients could rewatch her talk whenever - and as often - as they wish. She's bought a vid- 
eo camera and has a laptop.

Now what?!?

\section{Discussion question}

You are Anju's neighbour. As a teacher, she wants your advice - would a DVD be a good idea? What should she include in it, particularly for an ESL/EFL audience? Post your estimation in weeks in the Diabetes DVD discussion thread. Be sure to explain how you came up your answer.

\section{Trinh}

Trinh is an associate professor in museum studies at a comprehensive university. She has delivered an innovative introductory online course on museumology; in fact, students enrolled at universities in New Zealand, South Africa, and Finland all take her course. The course is delivered via Vista, features a range of multimedia educational artifacts, and guest lectures delivered via live streaming. Although participating in some of these activities is challenging for students in other time zones, they understand these are required activities and full participation is a condition of enrollment.

Trinh's committed to delivering learner-centred courses, whether taught $F 2 F$, online or blended. But this course - and its over 150 student enrollments - is challenging for her to manage. Email in particular can be onerous: on some mornings she finds dozens of messages. Some of these come to her university email address; others to her Vista email. She even gets student questions as comments to her blog!

Were this a F2F course, she would set up office hours - but that's not an option in an online course, is it? Post your ideas in the what could Trinh do discussion forum.

\section{Noelene}

Noelene teaches Grade 9 English at a private high school in the Sea-to-Sky corridor (along BC's Sea-to-Sky Highway 99, between Squamish and Pemberton, including Whistler). Getting her students to inculcate the practice of writing is challenging: bringing blogs into her curriculum seems like a great way to integrate purposeful learning activities with those many students already enjoy.

After doing some research she decides to use LiveJournal as the delivery platform for an activity she calls No, really: something kewl I discovered online this week. Noelene has created a community on LiveJournal called Something Kewl. Students must post once a week to the community, describing something noteworthy found online. Students need to set up their own blog on LJ (as it's called) in order to post to the community.

Students have the option of posting a draft version of their entry to their own blog, in order to receive formative feedback from Noelene. In each term a student earns up to 10 marks for their entries, so long as they are substantial and well-edited; anyone whose entire 10 entries are free of surface errors gets a bonus of 5 points. Each Friday the class reviews that week's entries, which are posted no later than Wednesday night.

The students love doing the activity, and she can see their writing improving. However two parents expressed concern about the activity because: 1.) it's public, and 2.) strangers have been commenting in their children's personal LJs.

How might Noelene address the concerns raised by the parents in a way that does not negatively impact the activity for the students? Are there justifications for having students work in public spaces on the web? 
Post your thoughts on this to the Public or private discussion forum under Module 4.

\section{Kwikwetlem (Raj)}

Raj is a grade 5 elementary school teacher in Coquitlam. His undergraduate degree was in biochemistry, and he finds it at times challenging to balance his passion for science with his responsibility to teach other subjects - particularly English Language Arts. That the BC IRP for grade 5 English cites "making personal connection to texts" as a goal makes him feel even more pressure: he has never really enjoyed reading fiction for leisure very much himself.

Raj fulfilled the requirement for admission to his B.Ed. program by taking a course on the history of Aboriginal peoples of Canada. He found the course very challenging because of its reading load, but the topic fascinated him and he did reasonably well as a result. In fact, when Raj can use history (rather than literature) texts for Language Arts, he's much more comfortable. Raj grew up in Coquitlam and really noticed how little of his K-12 schooling addressed his own community; as a result, he tries to bring as much Coquitlam and BC material into the classroom as possible. Raj has found one resource really helpful when developing lesson plans: the website The Far West: A History of BC (http://www.knowbc.com/learninglayer/farwestmain.html). There's a lot of great content there, particularly on Aboriginal history. But it's also very generic content, more often about the whole province rather than Coquitlam. It's also told largely from the perspective of Europeans, rather than Aboriginal persons.

Raj would like to create a self-directed, online learning module about the Kwikwetlem First Nation, delivered via a customized web site. The Kwikwetlem First Nation has its own website (http://www.kwikwetlem.com/home), but Raj thinks it's a bit too sophisticated for grade 5 students. He's also looked for something existing that might work, but nothing's come up so far.

Last weekend Raj visited the Kwikwetlem's Port Coquitlam reserve. Chief Percy Cunningham was very pleased Raj wanted to teach his students about Kwikwetlem history. He gave Raj a tour of the reserve and shared with him the story of the Kwikwetlem. He even agreed that Raj could videotape his storytelling and use the video for his lesson (Raj also took over 100 photos). The entire visit really inspired Raj-he's even more motivated to get working on this module! Raj has timetabled five hours of class time for this lesson (one hour per day for one week), beginning one month from now. However, his prep and marking obligations mean he will be working on this evenings and weekends. Raj estimates he could squeeze about 10 hours a week in total for the project.

\section{Discussion questions:}

What might be three (3) important questions Raj could ask himself when deciding which multimedia to include?

Do you think Raj can deliver this in a month? Explain your answer and either:

- Suggest how Raj approach developing his website?

- Offer an alternative to the website, one that will use some of Multimedia already collected.

\section{Dafna}

Dafna teaches Fine Arts in a Vancouver Board of Education (VBE) alternative high school program. Students there have, for various reasons, struggled in mainstream high 
school programmes. At her "school" a flexible structure, condensed (4 hour) day, and interdisciplinary approach to curriculum all result in increased attendance and improved grade 12 completion rates. Using classroom-based, small group and self-directed pedagogical approaches, students work through materials at their own pace, following Individual Learning Plans developed collaboratively. Currently the learning group Dafna facilitates has eight students studying Music 10.

Previously Dafna has created music videos of herself for her Music 10 Guitar students, which have been very well received. This year she has an even more exciting idea: having students make their own music videos of themselves.

The school has five (5) acoustic guitars available, and 4 iMac computers (which are used for other program components in addition to Music). Dafna has her own video camera and tripod, which students can borrow. Her Director has agreed to purchase 10 mini-DV cassettes for the project.

Because of the flexible nature of the programme, Dafna need only develop an estimated time for the lesson to be completed. She also has the option to make this an iterative tasks: one that students revisit from time to time over the course of several months. The iterative approach is more easily adapted to the school, so Dafna expects the activity to go something like this:

\begin{tabular}{|lll|}
\hline Activity & Time Needed & Notes \\
\hline Camera basics & 2 hours & Done in class \\
\hline Shooting video & 2 hours & Done in class and out in the neighbourhood \\
\hline Editing video & 10 hours & Capture, cropping, transitions, soundtrack, titles \\
\hline Post-production & 5 hours & Export to DVD, iPod formats \\
\hline
\end{tabular}

\section{Discussion questions}

1. Based on the resources available, how might Dafna organize this activity?

2. How might she disseminate the music videos, once created?

\section{LMS Evaluation Rubric Scenarios}

In addition to the narratives ETEC565A students explored with the class a whole, everyone also completed one small group activity featured five different scenarios, with students assigned to a working group. Each working group was given a scenario related to selecting an LMS platform, and were asked to develop an LMS evaluation rubric key decision makers could apply when evaluating various LMS products.

After each group finalized its rubric, they posted theirs (along with a précis of the scenario they were given) to the entire class. Each learner then had to give formative feedback on the other working groups' works.

The five scenarios were as follows:

1. Humanities 101: Margo Fryer, the Director of UBC Exchange's Humanities 101 programme asks you to sit on the Online Learning Development committee. As part of the Online Learning Development committee, you need to develop a strategy for selecting a possible LMS, primarily to create a space where lecturers who cannot attend face-to-face can still share their expertise with program students. 
2. BC SD (School District) 63: You are teachers in the South Island Distance Education School's (SIDES) Secondary program. SIDES, a program of SD 63 on Vancouver Island, provides distance learning support to a range of home schooled children in the district. There is increasing international interest in students enrolling in your programs, leading to a $\mathrm{BC}$ dogwood high school diploma. Current estimations are that initial enrolment could easily exceed 200 students.

3. Douglas College Nursing: You are Clinical Faculty Associates in Douglas College's Bachelor of Science Nursing (BSN) program. The BSN program relies significantly on the Health Sciences Simulation Centre (HSSC) labs prior to students entering their first practicum. Two cohorts of students have gone through their initial HSSC rotation, and the feedback has been largely positive. However, many students expressed a desire for an online space where they can: 1.) discuss their experiences with faculty and peers; and 2.) access electronic versions of simulation output for further reflection and study during each HSSC rotation

4. Royal Roads MBA in China: Interest in Royal Roads University's MBA in Greater China has been huge! There's no shortage of ambitious, qualified students; in fact, university leadership has determined that the enrolment can be increased to up to 800 new students per cohort. There are 3 cohorts each year: September, January, and May. But the increased student numbers has also seen an increase in server "issues," i.e. crashes. Current technology is used to support Royal Roads' entire distance education requirements.

5. Little Flower Academy: You are Social Studies ("Socials") teachers at Vancouver's Little Flower Academy. One of your colleagues (Mrs. Egan) has been using a web page to distribute materials. A number of parents are unimpressed with how she's doing it: they're concerned about privacy and don't think the design of the pages is very professional. To be fair, Mrs. Egan has been arguing that the school needs to adopt a "proper" LMS for these sorts of things.

Seeing how the same ostensive challenge - developing technology selection evaluation rubricwas responded to differently allows learners to validate - and interrogate - their individual approaches to the task. Having each produced a detailed evaluation rubric - drawing up course materials and key literatures - makes comparing rubrics with different structures developed for a specific scenario, nonetheless manageable....and is a constructivist activity that leads to deeper learning.

\section{Reception}

When employing active learning strategies, a balance between providing adequate details. And while leaving an open enough canvas for exploration is key. In a course like ETEC 565A we felt it important that we not only build robust individual learning activities; we also needed to create a cohesive series of activities. Each focuses on issues covered in that unit or module, but as the course progresses, the narratives - and discussion questions that accompany each-become more sophisticated.

The first and penultimate narratives are purposefully similar: both Dafna and Benoit's narratives feature the same question: estimation of project scope. By posing the Dafna case last we highlight how learners' reasoning has evolved over the course of the term.

Since May 2009's first offerings of three concurrent sections (71 students in total), ETEC 565A has been offered seven more times: by August 2011 over 200 students will have completed the course, which has quickly become most in-demand offering in the program. Student evaluation data has consistently shown the course to be very valuable to MET learners, with the course rated 
consistently as "excellent". In terms of qualitative feedback, the course-including these learning activities - are often cited:

I have taken six previous MET course online and this was simply the best yet. The applied nature of the course was exactly what I needed at this stage of the program (although I regret not taking it earlier). Frankly, I feel this course should be a core requirement for the MET program.

A lot of things started clicking in this course that didn't previously. I would recommend that everyone in the program take this course. I can see myself actually implementing several of the tools we learned in my school next year.

The quality of the assignments were excellent and were very useful and used local examples from BC which struck a chord with me.

We have made adjustments to the course design - smaller, incremental ones largely to more clearly communicate process aspects of the course - after each offering, based on the SEoT data made available. There is also significant student interest in a subsequent course that offers additional, more advanced competencies.

\section{Lessons Learned}

In reflecting upon this process I hope others working in similar programs can use the MET experience as an exemplar of how to integrate narrative active learning into sophisticated course design.

This very much is a Canadian course with a Canadian orientation and ethos; doubtless this work is not linearly transferable to many contexts. But the core design principles and practices we employed hopefully are:

- Identification of competencies and shape them into a coherent framework;

- Mapping out a trajectory that allows learners to incremental acquire competencies with increasing complexity;

- Use fictive scenarios that require learners to seek appropriate additional sources;

- Design of activities that require learners to work collaboratively, both formally and informally; and

- Adaptation and adjust the materials as appropriate, based on learner feedback.

\section{References}

Audet, R. (2005). Inquiry: A continuum of ideas, issues, and practices. In R. Audet \& L. Jordan (Eds.), Integrating inquiry across the curriculum (pp. 5-15). Thousand Oaks: Corwin Press.

Anderson, T. (2008). Towards a theory of online learning. In T Anderson \& F. Elloumi, Theory and practice of online learning. Athabasca University.

Bates, A. W., \& Poole, G. (2003). Chapter 4: A framework for selecting and using technology. In A. W. Bates \& G. Poole, Effective teaching with technology in higher education: Foundations for success (pp. 77-105). San Francisco: Jossey Bass.

Biggs, J. (2003). Teaching for quality learning at university. New York: Open University Press. 
Chickering, A. W., \& Gamson, Z. F. (1987). Seven principles for good practice in undergraduate education. American Association for Higher Education Bulletin, 39 (7), 3-7.

Chickering, A. W., \& Ehrmann, S. C. (1996). Implementing the seven principles: Technology as lever. American Association for Higher Education Bulletin, 49(2), 3-6.

Colburn, A. (2000). An inquiry primer. Science Scope, 23(6), 42-44.

McNiff, J., Lomax, P., \& Whitehead, J. (1996). You and your action research project. New York: Routledge.

Piaget, J. (1950). The psychology of intelligence. New York: Routledge.

Voorhees, R. (Ed) (2001). New directions for institutional research: Measuring what matters Competencybased learning models in higher education (No. 110). San Francisco, CA: Jossey-Bass.

\section{Biography}

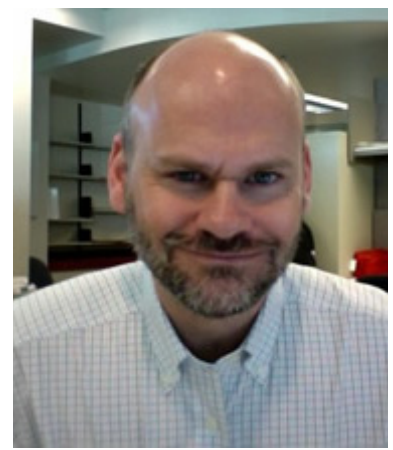

John P Egan, PhD is the Senior Manager, Strategic Curriculum Services at the University of British Columbia's Centre for Teaching, Learning and Technology. He has many years' experience as a curriculum developer, instructor, facilitator, course designer, program administrator, and educational researcher in the community, adult, corporate, private post-secondary and university sectors in Canada and internationally. John has also been published widely in the fields of education and health. His work has been published in The Journal of Interprofessional Care, Studies in the Education of Adults, Convergence, and the Canadian Journal for the Study of Adult Education. 